\title{
Impact of Elevated Atmospheric Carbon Dioxide on Yield, Vitamin C, Proximate, Fatty Acid and Amino Acid Composition of Capsicum (Capsicum Annuum)
}

\author{
Andaleeb Azam ${ }^{1 *}$, Abdul Hameed ${ }^{2}$, Ikhtiar Khan ${ }^{3}$ \\ ${ }^{1}$ Department of Chemistry, Women University Swabi, Swabi, KP, Pakistan \\ ${ }^{2}$ National Center for Nanoscience and Technology, Haidian, Beijing, China \\ ${ }^{3}$ Institute of Chemical Sciences, University of Peshawar, Pakistan \\ *Email: andaleebazam1@gmail.com
}

\begin{abstract}
A steady increase in the atmospheric $\mathrm{CO}_{2}$ concentration due to human activities in the last few decades is largely believed to be a major cause of climate change. Since agriculture is a climate sensitive system, there is a growing concern that the $\mathrm{CO}_{2}$ added to the air is changing the nutritional composition of fruits, grains and vegetables. Based on this hypothesis, the present experiment work was conducted to study the effect of enhanced atmospheric $\mathrm{CO}_{2}$ on nutritional and biochemical composition of chili (Capsicum annuum). Five local varieties of capsicum (Angrika, Best Choice, Diana, Magama, and 99PE-1689) were grown under two concentrations of $\mathrm{CO}_{2}$, i.e. 400umol $\mathrm{mol}^{-1}$ (ambient) and $1000 \mu \mathrm{mol} \mathrm{mol}^{-1}$ (elevated) under controlled conditions in green houses. Fruits were harvested at two stages of maturity and analyzed for proximate, elemental, fatty acid and amino acid concentration. Capsicum fruits grown under higher $\mathrm{CO}_{2}$ concentration had different nutritional composition.Vitamin $\mathrm{C}$, protein, ash and fat contents decreased significantly $(P \leqslant 0.05)$, acidity decreased non-significantly $(P>0.1)$ whereas sugar and fiber contents increased significantly under enhanced $\mathrm{CO}_{2}$. Elemental composition showed a significant increase in $\mathrm{C}, \mathrm{H}, \mathrm{Fe}, \mathrm{Mn}$ and a decrease in $\mathrm{N}, \mathrm{Ca}, \mathrm{Mg}$ and $\mathrm{Zn}$ contents. Few elements ( $\mathrm{S}, \mathrm{K}$ and $\mathrm{Cu}$ ) showed no significant trend with elevated $\mathrm{CO}_{2}$. Fatty acids, with few exceptions, were not much affected by $\mathrm{CO}_{2}$ enrichment. Amino acids decreased with elevated concentration of $\mathrm{CO}_{2}$. The effect of enhanced $\mathrm{CO}_{2}$ was more pronounced at the fully matured (red) stage as compared to the pre-mature (green) stage of capsicum fruit. Enhanced atmospheric $\mathrm{CO}_{2}$ lowered the nutritional quality of capsicum fruit by decreasing its vitamin $\mathrm{C}$, proteins, $\mathrm{Ca}, \mathrm{Mg}$ and $\mathrm{Zn}$ contents.
\end{abstract}

Keywords: Atmospheric $\mathrm{CO}_{2}$, capsicum, nutritional quality, elemental composition.

\section{Introduction}

Industrial revolution has changed the composition of natural atmosphere with increased amount of greenhouse gases and other pollutants. Concentration of carbon dioxide $\left(\mathrm{CO}_{2}\right)$ has increased from a preindustrial value of $280 \mathrm{ppm}$ to the present concentration of $380 \mathrm{ppm}[1]$. With human activities like combustion of fuel, deforestation and desertification continued at the current rate, concentration of atmospheric $\mathrm{CO}_{2}$ is expected to cross $550 \mathrm{ppm}$ by mid-century and could double by end of this century[2]. Agricultural products are expected to be affected by any change in the atmospheric composition particularly an increase in $\mathrm{CO}_{2}$, which is used as a raw material in photosynthesis. An increase in the concentration of atmospheric $\mathrm{CO}_{2}$ is expected to increase the edible biomass of agricultural products by increasing growth and yield of plants and vegetables [3-6]. Many chemical changes can also occur in plants as a result of elevated levels of $\mathrm{CO}_{2}$. Studies related to this hypothesis have mostly been concentrated on the growth and yield of the food crops, whereas its possible impact on the nutritional balance and elemental composition has been ignored. Available studies are predominantly on crops like wheat, maize, rice and potato, and very little information is in fact available on vegetables.

Capsicum is a plant that belongs to the Solanaceae family and is classified under vegetable fruit. Capsicum varieties are used worldwide as raw or cooked food, for preparation of pickles, making pastas 
and sauces, as well as to produce spice in the food. It is either used fresh or preserved by open air drying. Capsicum has a number of medicinal uses worldwide[7].

Capsicum is an important source of vitamin C. It is comparable to other vitamin $\mathrm{C}$ rich vegetables and even citrus fruits in some cases[8]. It also contains high levels of vitamin A, E and B complex as well as antioxidants, aromas and natural colors [9] [10]. The quality of capsicum greatly varies and is affected by a number of factors; one major factor is the environmental conditions under which it is cultivated[11].

Elevated atmospheric $\mathrm{CO}_{2}$ affects Capsicum annuum in different ways. It increases the growth rate and yield of the plant but has no effect on the chlorophyll content[12]. An increase in $\mathrm{CO}_{2}$ concentration in the ambient air is also known to reduce the rate of transpiration in pepper plants [13]. Pulse - rate enhancement in $\mathrm{CO}_{2}$ concentration has been found to decrease growth and yield of capsicum and increase visual injuries in the plant as compared to a constant increase in $\mathrm{CO}_{2}$, which increased the plant growth and yield but did not cause injuries[12]. The $\mathrm{CO}_{2}$ enrichment in plastic greenhouse also increased fruit length, weight, and diameter and fruit number per plant of Capsicum annuum [14]. Elevated $\mathrm{CO}_{2}$ concentration reduced sucrose concentration in the pollen of Capsicum annum by increasing their utilization for pollen germination under high temperature stress[15]. $\mathrm{CO}_{2}$ is known for its effect on physiology and mortality of insects. In case of Capsicum annuum, the effect was studied on thrips and whiteflies, and it was found that higher $\mathrm{CO}_{2}$ levels do not affect the insects directly but decrease the insect population indirectly by changing the plant metabolism[16]. In the present experimental work the effect of enhanced atmospheric $\mathrm{CO}_{2}$ on the quality parameters of Capsicum annuum including proteins, carbohydrates, fats, fiber, ash contents, vitamin C, acidity and sugars (i.e. total sugars, reducing and non-reducing sugars), elemental composition (C, H, N, S, Fe, Ca, Mg, Zn, Mn, $\mathrm{K}, \mathrm{Cu}$ ) fatty acid and amino acid composition was investigated.

\section{$2 \quad$ Materials and Methods}

\subsection{Experimental Design}

Five local varieties of Capsicum cvs.; Angrika, Best Choice, Diana, Magama, and 99PE-1689 were selected for the study. Seeds were grown and harvested in proper seasons. Clay pots with $30 \mathrm{~cm}$ diameter and $45 \mathrm{~cm}$ depth were used for growing the plants. Pots were placed in greenhouses made of glass. Two different $\mathrm{CO}_{2}$ concentrations (400 and $1000 \mu \mathrm{mol} \mathrm{mol}{ }^{-1}$ ) were maintained in the greenhouses. Carbon dioxide gas was released from cylinder through a pipe alongside the plant rows. Pipe height from the ground level was regularly adjusted to the plant canopy. The concentration of $\mathrm{CO}_{2}$ was measured frequently with a Gas Analyzer (MX-42 an Oldham, France).

Soil of sandy clay loam texture was used for growing plants. Soil characteristics like electrical conductivity $(0.65 \mathrm{~d} \mathrm{~S} / \mathrm{m})$ and $\mathrm{pH}(7.9)$ were recorded. Organic matter in soil $(5.6 \mathrm{~g} / \mathrm{Kg})$, total nitrogen $(0.032 \%)$, available phosphorous (11.4 $\left.\mathrm{mg} \mathrm{Kg}^{-1}\right)$, extractable potassium(148 $\left.\mathrm{mg} \mathrm{Kg}^{-1}\right)$, EDTA Zn (1.8 mg $\left.\mathrm{Kg}^{-1}\right)$, EDTA $\mathrm{Cu}\left(2.4 \mathrm{mg} \mathrm{Kg}^{-1}\right)$ and EDTA Mn in the soil $\left(4.2 \mathrm{mg} \mathrm{Kg}^{-1}\right)$ were all measured

Temperature of the air inside the green houses was continuously monitored during the experimental period and recorded. Average temperature during the growing season was $23.2^{\circ} \mathrm{C}$ with a maximum temperature of $34.1^{\circ} \mathrm{C}$ and minimum of $14.2^{\circ} \mathrm{C}$.

Details of the experimental design, soil characteristics, greenhouses construction, $\mathrm{CO}_{2}$ treatment, plant cultivation and harvest procedures have been described earlier (Khan et al., 2013).

\subsection{Fruit Harvest and Analysis}

Fruits of Capsicum annum were harvested at two stages of maturity, green and red. Fresh samples were used for analysis of total acidity and vitamin C, for the rest of analysis dried sample was used. Analysis of fruit sample was carried out using standard methods available in the literature. Analysis of ash, fat, vitamin $\mathrm{C}$, total titrable acidity and sugars were carried out according to the methods of Association of Official Analytical Chemists (AOAC, 2000). Fat contents were determined by soxhlet extractor using nhexane solvent and ash by muffle furnace. Crude fiber was determined from the defatted material left after fat extraction by digestion with dilute acid followed by dilute base. Protein contents were 
determined on the basis of total nitrogen with a conversion factor of 6.25 and nitrogen was determined with the help of CHNS elemental analyser (Vario EL III CHNS-O Elemental Analyser GmbH). Total titrable acidity was determined by titration of aqueous extract against standard alkali solution. Vitamin $\mathrm{C}$ was extracted from the fruit with the $15 \%$ solution of metaphosphoric acid and titrated against 2, 6dichlorophenol indophenol dye. The dye was standardized with standard ascorbic acid solution. Sugars were determined by Lane and Eynon titrimetric method as mentioned in AOAC (2000). Reducing sugars were determined by titrating aqueous extract of plant material against Fehling's solution. Nonreducing sugars were converted to reducing sugars with citric acid and the total sugars were determined by the same method. Non-reducing sugars were determined from the difference of the two.

CHNS elemental analyzer (Vario EL III CHNS-O Elemental Analyser GmbH) was used for the determination of $\mathrm{C}, \mathrm{N}, \mathrm{S}$ and $\mathrm{H}$ (AOAC, 2000) while the rest of the elements (Fe, Ca, Mg, Zn, Mn, K, $\mathrm{Cu}$, ) were determined with atomic absorption spectrophotometer (AAS- Perkin Elmer, Analyst 700) (Allen et al., 1986).

GC-MS (Shimadzu Model QP 2010 plus) was used for the determination of fatty acids by the internal standard method. Fatty acids present in oil of the fruit were first converted to methyl esters of fatty acids (FAME) and then injected to GC-MS, using tridecanoic acid methyl ester as internal standard (AOAC, 2000).

Amino acids were extracted from the sample using $0.1 \mathrm{~N} \mathrm{HCl}$ and analyzed. Analysis was carried out using HPLC based amino acid analyzer (Schimadzu, Model LC-20AD) equipped with fluorescent detector (RF-10AXL) (AOAC, 2000).

\subsection{Statistical Analysis}

Results of triplicate analysis are expressed as mean value \pm standard deviation. Significance of the data was found from the value of probability level $(P)$ obtained by subjecting the data to Student's t-test with software SPSS 16.0. The results were considered significant at $P \leqslant 0.05$, trend at $0.05<P \leqslant 0.1$ and non-significant at $P>0.1$.

\section{Results}

Elevated $\mathrm{CO}_{2}$ significantly increased the number of fruits per plant for all five varieties of capsicum. Increase in number of fruits per plant was in the range of 34.61 to $50.00 \%$ and increase in the fresh weight was in the range 43.80 to $59.55 \%$ (Fig. 1A\& B)

Amongst the proximate composition parameters, protein and vitamin $\mathrm{C}$ were reduced, while sugars and fibers contents were increased by elevated atmospheric $\mathrm{CO}_{2}$. Protein content was studied for three varieties of capsicum. Highest amount of protein was present in the Magama variety (21.01\%) and lowest amount was present in 99PE-1689 (12.29\%). Elevated $\mathrm{CO}_{2}$ significantly decreased the protein content of capsicum (Fig. 2). The decrease was highest for Best Choice variety (31.62\%) and lowest for Magama (25.10\%).

The major sugars in capsicum are reducing sugars (glucose + fructose) with small quantity of nonreducing sugar (sucrose). Enhanced level of $\mathrm{CO}_{2}$ significantly increased sugar contents of capsicum (Fig. $3 \mathrm{~A}$ ). Both reducing sugars and non-reducing sugars were increased for all five varieties of capsicum. The increase was non-significant for non-reducing sugars. Elevated $\mathrm{CO}_{2}$ increased the fiber content of capsicum varieties. For red fruits, the increase ranged between 6.09 and $9.03 \%$, and for green fruits it ranged between 3.19 and $4.71 \%$. Increase in fiber content was significant for matured fruits and followed a trend for premature fruits (Fig. 3B).

Enhanced atmospheric $\mathrm{CO}_{2}$ decreased vitamin $\mathrm{C}$ significantly in capsicum varieties (Fig. 4A). The decrease ranged between 11.84 and $15.84 \%$ for the matured stages and 8.98 to $12.12 \%$ for green stages. Total titratable acidity of the red fruits of capsicum was slightly higher than premature green fruits, and it decreased with elevated $\mathrm{CO}_{2}$ non-significantly $(P>0.1)$ (Fig. $\left.4 \mathrm{~B}\right)$.

Increased atmospheric $\mathrm{CO}_{2}$ affected the mineral composition of capsicum varieties. A significant increase was observed for some minerals like $\mathrm{H}, \mathrm{Fe}$ and $\mathrm{Mn}$ while many other important minerals were reduced including $\mathrm{Ca}, \mathrm{Mg}$ and $\mathrm{Zn}$. No significant trend was observed for $\mathrm{K}$ and $\mathrm{Cu}$. $\mathrm{Cu}$ tended to decrease in 99PE-1689 $(0.05<P \leqslant 0.1)$ (Fig 5, 6 and 7$)$. 
Probability level $(P)$ obtained from t test

\begin{tabular}{c|c|c}
\hline Parameter & Fruit no. & Fruit Weight \\
\hline 99PE-1689 & $(0.073)$ & 0.001 \\
\hline Magama & 0.031 & 0.008 \\
\hline Angrika & 0.024 & 0.005 \\
\hline Best Choice & $(0.072)$ & 0.007 \\
\hline Diana & $(0.069)$ & 0.005 \\
\hline
\end{tabular}

(A)

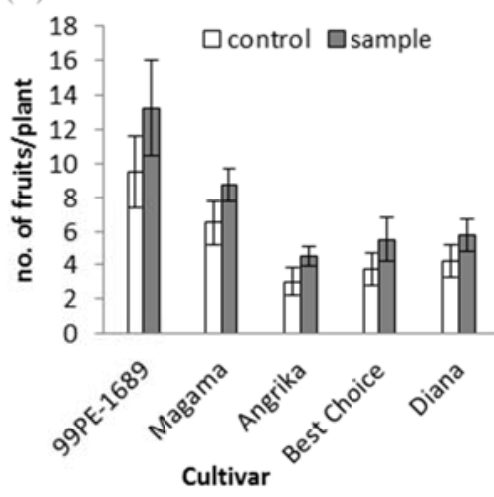

(B)

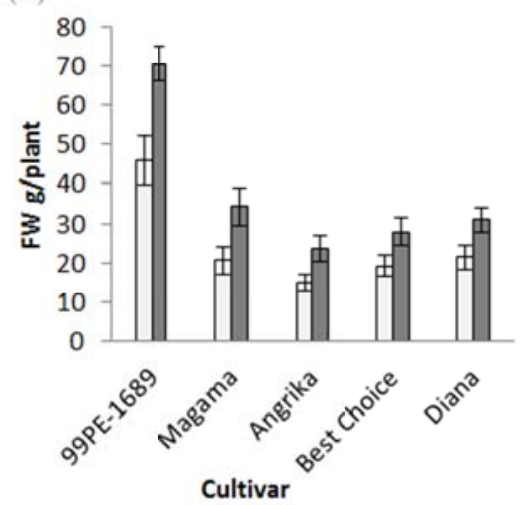

Figure 1. Effect of elevated atmospheric $\mathrm{CO}_{2}$ on yield of capsicum fruits, (A) number of fruits per plant and (B) fresh weight in terms of $\mathrm{g} /$ plant. White histograms represent the data for control plants grown at $400 \mathrm{\mu mol} \mathrm{mol}^{-}$ ${ }^{1}$ and black histogram showing result for sample plants grown at $1000 \mu \mathrm{mol} \mathrm{mol}{ }^{-1}$. ns represents non-significant data $(P>0.1)$ and number in parenthesis indicate trend $(0.05<P \leqslant 0.1)$.

Probability level $(\mathrm{P})$ obtained from $\mathrm{t}$ test

\begin{tabular}{c|c|c|c}
\hline Parameter & 99PE-1689 Red & Magama Red & Best Choice Red \\
\hline Protein & 0.024 & 0.004 & 0.002 \\
\hline
\end{tabular}




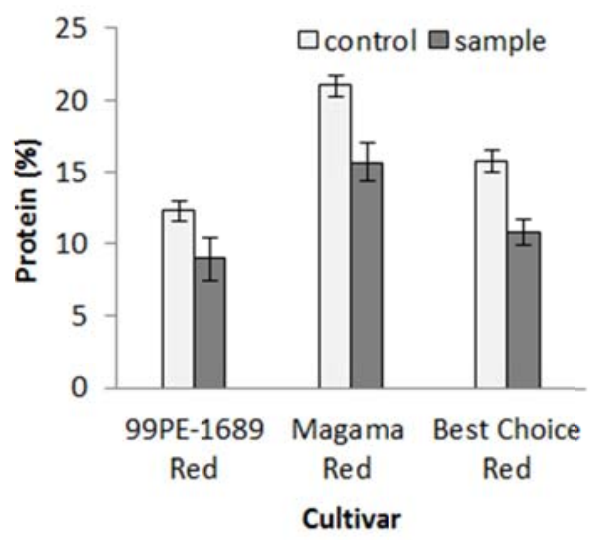

Figure 2. Effect of elevated atmospheric CO2 on protein (\%) of capsicum fruits. White histograms represent the data for control plants grown at $400 \mathrm{\mu mol} \mathrm{mol-1and} \mathrm{black} \mathrm{histogram} \mathrm{showing} \mathrm{result} \mathrm{for} \mathrm{sample} \mathrm{plants} \mathrm{grown} \mathrm{at} 1000$ umol mol-1. ns represents non-significant data $(\mathrm{P}>0.1)$ and number in parenthesis indicate trend $(0.05<\mathrm{P} \leqslant 0.1)$.

Fatty acids were determined for two varieties of capsicum, 99PE-1689 and Best Choice. Although the response of different fatty acids to elevated atmospheric $\mathrm{CO}_{2}$ was not similar, generally a decreasing trend was observed (Table 1). Lauric acid increased very slightly for 99PE-1689 and remained unchanged for Best Choice. Myristic acid increased for both varieties. Pentadecanoic acid, palmitoleic acid, margaric acid and tricosanoic acid remained almost unaffected by elevated $\mathrm{CO}_{2}$ for both verities. Palmitic acid, stearic acid, oleic acid, linoleic acid, octadecadienoic acid, arachidic acid, behenic acid and tetracosanoic acid decreased for both varieties of capsicum. Elaidic acid and linolenic acid decreased for 99PE-1689 and increased for Best Choice.

Amino acids composition was determined for three varieties of capsicum. Almost all of the amino acids analyzed in capsicum varieties decreased under elevated $\mathrm{CO}_{2}$ conditions. A slight increase was observed only for Val, Tyr and Arg in some varieties of capsicum (Table 2).

Probability level $(\mathrm{P})$ obtained from $\mathrm{t}$ test

\begin{tabular}{c|c|c}
\hline Parameter & Total sugars & Fibers \\
\hline 99PE-1689 Red & 0.005 & 0.003 \\
\hline 99PE-1689 Green & 0.021 & $(0.056)$ \\
\hline Magama Red & 0.004 & 0.003 \\
\hline Magama Green & - & $0.069)$ \\
\hline Angrika Red & 0.007 & 0.013 \\
\hline Angrika Green & - & $0.067)$ \\
\hline Best Choice Red & 0.001 & 0.006 \\
\hline Diana Red & 0.021 & 0.023
\end{tabular}




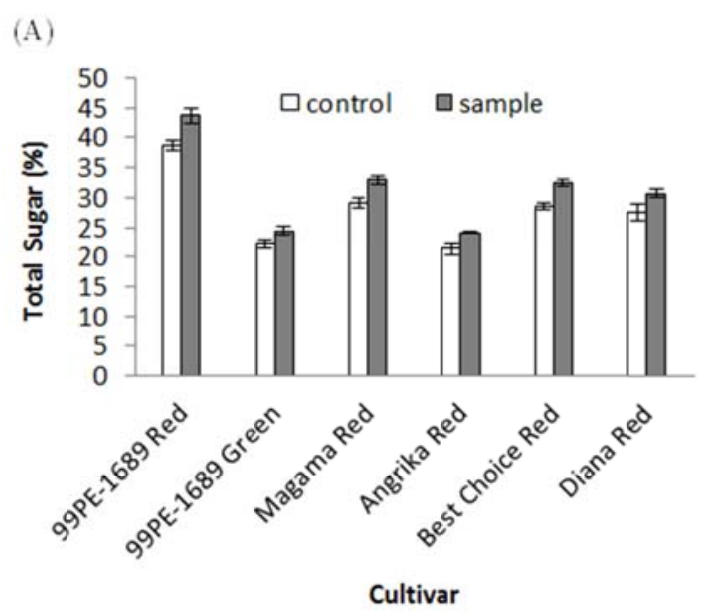

(B)

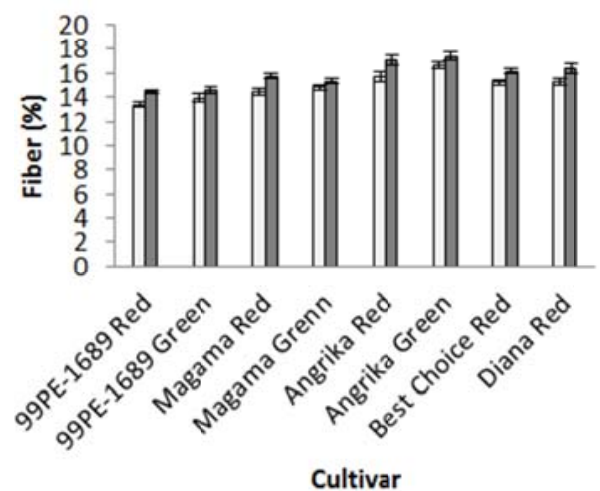

Figure 3. Effect of elevated atmospheric CO2 on (A) total sugars (\%) and (B) fiber content (\%) of capsicum fruits. White histograms represent the data for control plants grown at $400 \mu \mathrm{mol} \mathrm{mol}-1$ and black histogram showing result for sample plants grown at $1000 \mu \mathrm{mol}$ mol-1. ns represents non-significant data $(\mathrm{P}>0.1)$ and number in parenthesis indicate trend $(0.05<\mathrm{P} \leqslant 0.1)$.

Probability level (P) obtained from t test

\begin{tabular}{c|c|c}
\hline Parameter & Vitamin C & Total titratable acidity \\
\hline 99PE-1689 Red & 0.001 & $\mathrm{Ns}$ \\
\hline 99PE-1689 Green & 0.008 & $\mathrm{Ns}$ \\
\hline Magama Red & 0.001 & $\mathrm{Ns}$ \\
\hline Magama Green & 0.003 & $\mathrm{Ns}$ \\
\hline Angrika Red & 0.002 & $\mathrm{Ns}$ \\
\hline Angrika Green & 0.002 & $\mathrm{Ns}$ \\
\hline Best Choice Red & 0.004 & $\mathrm{Ns}$
\end{tabular}




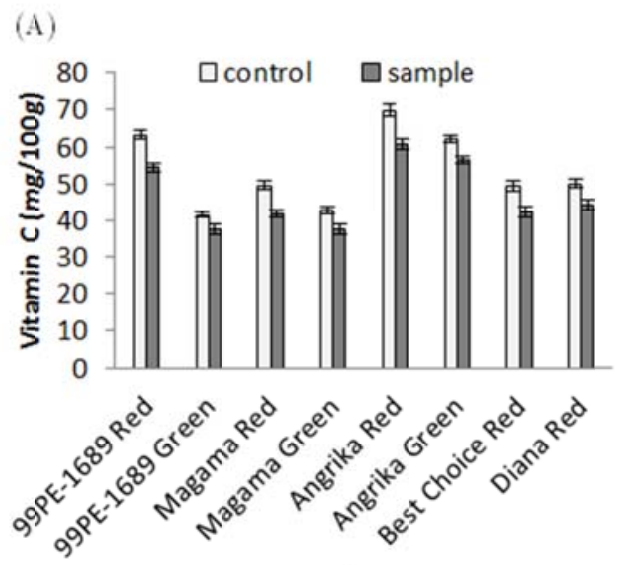

Cultivar

(B)

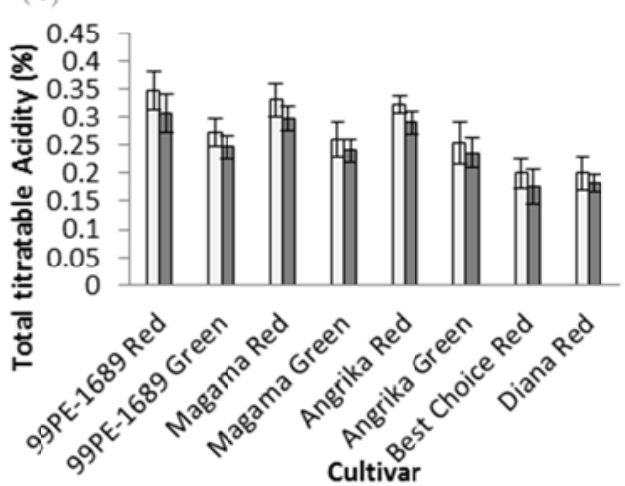

Figure 4. Effect of elevated atmospheric $\mathrm{CO} 2$ on (A) vitamin $\mathrm{C}(\mathrm{mg} / 100 \mathrm{~g})$ and (B) total titratable acidity (\%) of capsicum fruits. White histograms represent the data for control plants grown at 400 umol mol-1 and black histogram showing result for sample plants grown at $1000 \mu \mathrm{mol}$ mol-1. ns represents non-significant data $(\mathrm{P}>0.1)$ and number in parenthesis indicate trend $(0.05<\mathrm{P} \leqslant 0.1)$.

Probability level (P) obtained from t test

\begin{tabular}{c|c|c}
\hline Parameter & Sulphur & Hydrogen \\
\hline 99PE-1689 Red & ns & 0.001 \\
\hline Magama Red & ns & 0.010 \\
\hline Best Choice Red & ns & 0.004 \\
\hline
\end{tabular}



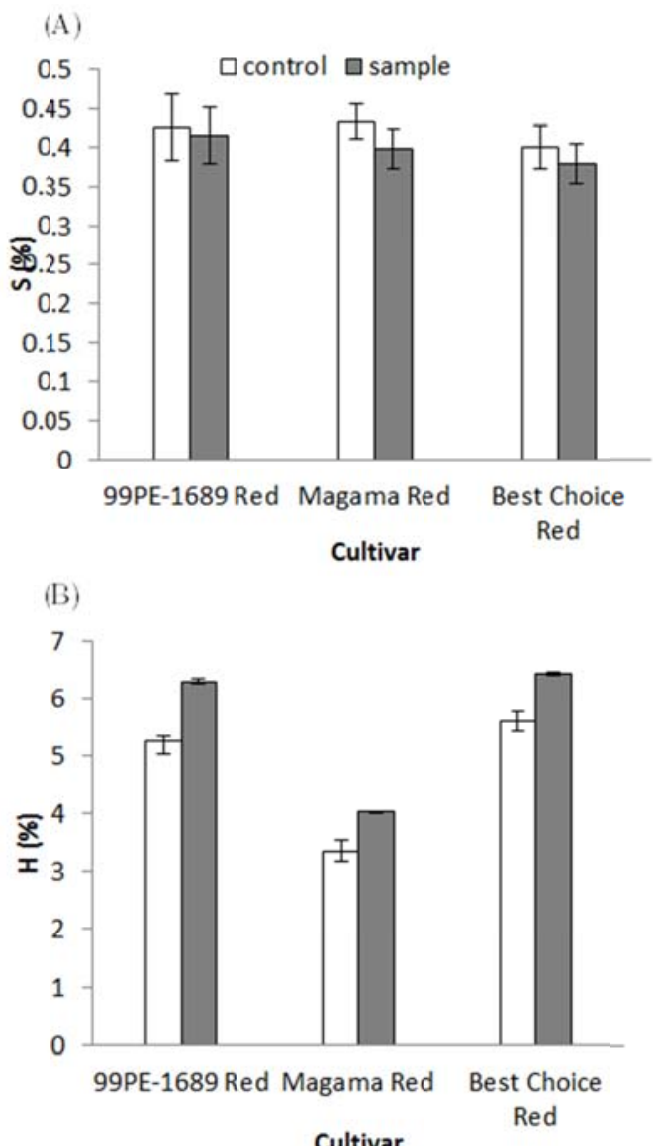

Figure 5. Effect of elevated atmospheric $\mathrm{CO} 2$ on (A) sulphur (\%) and (B) hydrogen (\%) contents of capsicum fruits. White histograms represent the data for control plants grown at $400 \mu \mathrm{mol}$ mol-1and black histogram showing result for sample plants grown at $1000 \mu \mathrm{mol}$ mol-1. ns represents non-significant data $(\mathrm{P}>0.1)$ and number in parenthesis indicate trend $(0.05<\mathrm{P} \leqslant 0.1)$.

Probability level (P) obtained from t test

\begin{tabular}{c|c|c|c}
\hline Parameter & Calcium & Magnesium & Potassium \\
\hline 99PE-1689 Red & 0.003 & 0.007 & $\mathrm{Ns}$ \\
\hline Magama Red & 0.019 & 0.001 & $\mathrm{Ns}$ \\
\hline Angrika Red & 0.016 & 0.001 & $\mathrm{Ns}$ \\
\hline Best Choice Red & 0.022 & 0.001 & $\mathrm{Ns}$ \\
\hline Diana Red & 0.017 & 0.005 & $\mathrm{Ns}$ \\
\hline
\end{tabular}


(A)

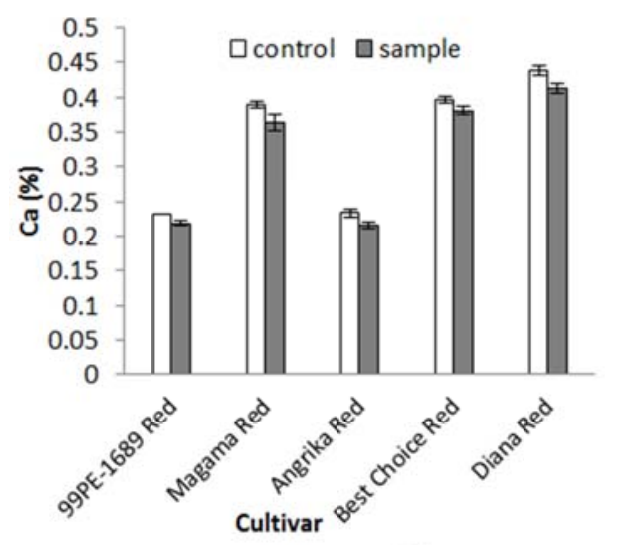

(C)
(B)

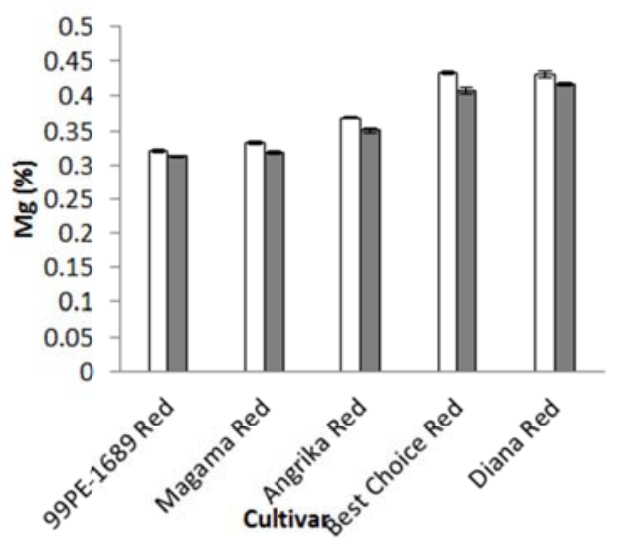

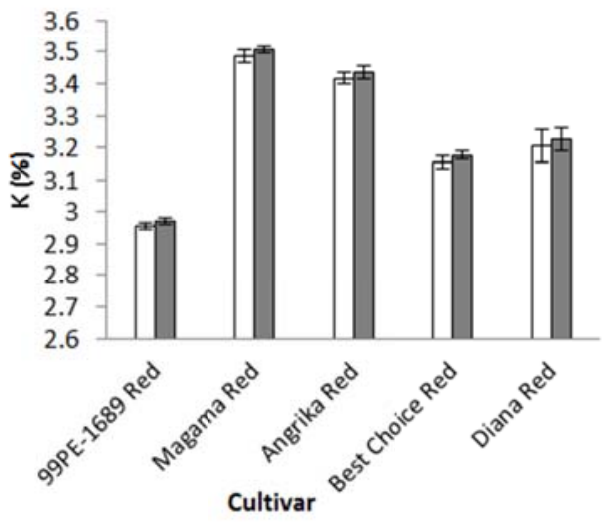

Figure 6. Effect of elevated atmospheric $\mathrm{CO} 2$ on macro mineral content of capsicum fruits, (A) Calcium (\%), (B) Magnesium (\%) and (C) Potassium (\%). White histograms represent the data for control plants grown at $400 \mu \mathrm{mol}$ mol-1and black histogram showing result for sample plants grown at $1000 \mu \mathrm{mol}$ mol-1. ns represents non-significant data $(\mathrm{P}>0.1)$ and number in parenthesis indicate trend $(0.05<\mathrm{P} \leqslant 0.1)$.

Probability level (P) obtained from t test

\begin{tabular}{c|c|c}
\hline Parameter & Zinc & Copper \\
\hline 99PE-1689 Red & 0.004 & $(0.056)$ \\
\hline Magama Red & 0.021 & Ns \\
\hline Angrika Red & 0.024 & Ns \\
\hline Best Choice Red & 0.022 & Ns \\
\hline Diana Red & 0.008 & Ns \\
\hline
\end{tabular}



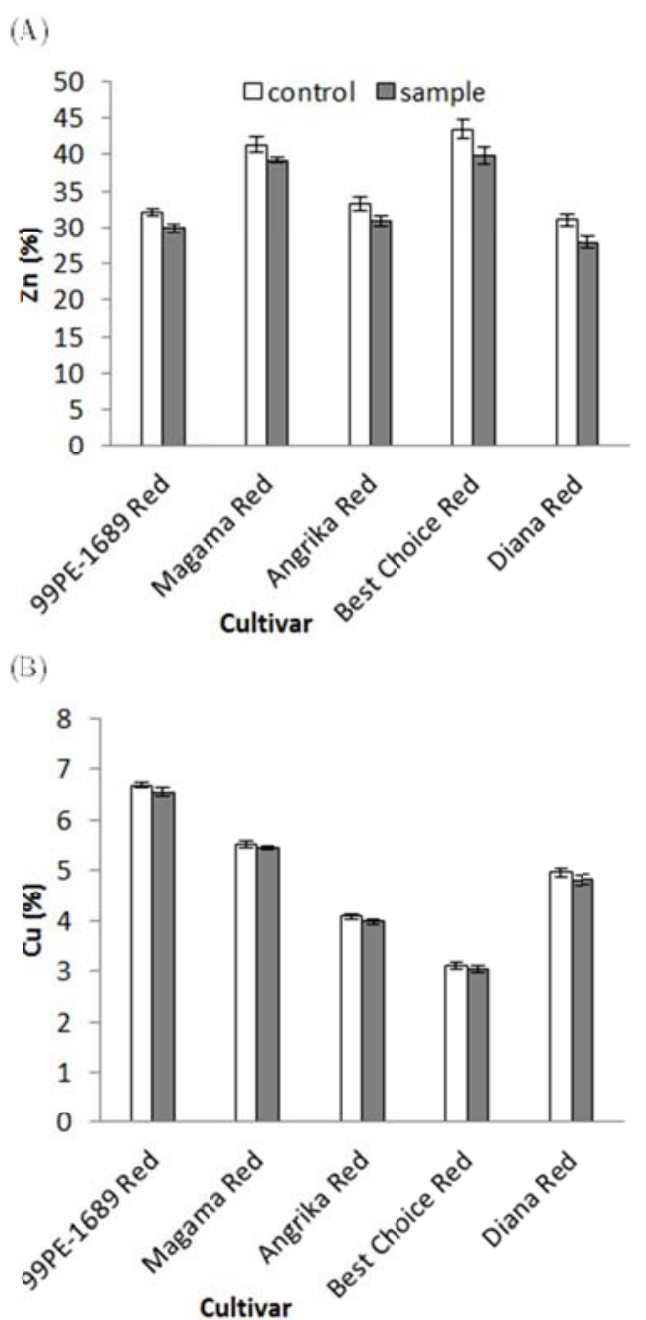

Figure 7. Effect of elevated atmospheric CO2 on micro mineral content of capsicum fruits, (A) Zinc (\%) and (B) Copper (\%). White histograms represent the data for control plants grown at 400 mol mol-1and black histogram showing result for sample plants grown at $1000 \mu \mathrm{mol}$ mol-1. ns represents non-significant data $(\mathrm{P}>0.1)$ and number in parenthesis indicate trend $(0.05<\mathrm{P} \leqslant 0.1)$.

Probability level $(\mathrm{P})$ obtained from $\mathrm{t}$ test

\begin{tabular}{c|c|c}
\hline Parameter & Iron & Manganese \\
\hline 99PE-1689 Red & $<0.001$ & 0.006 \\
\hline Magama Red & $<0.001$ & $<0.001$ \\
\hline Angrika Red & $<0.001$ & $<0.001$ \\
\hline Best Choice Red & $<0.001$ & $<0.001$ \\
\hline Diana Red & $<0.001$ & $<0.001$ \\
\hline
\end{tabular}



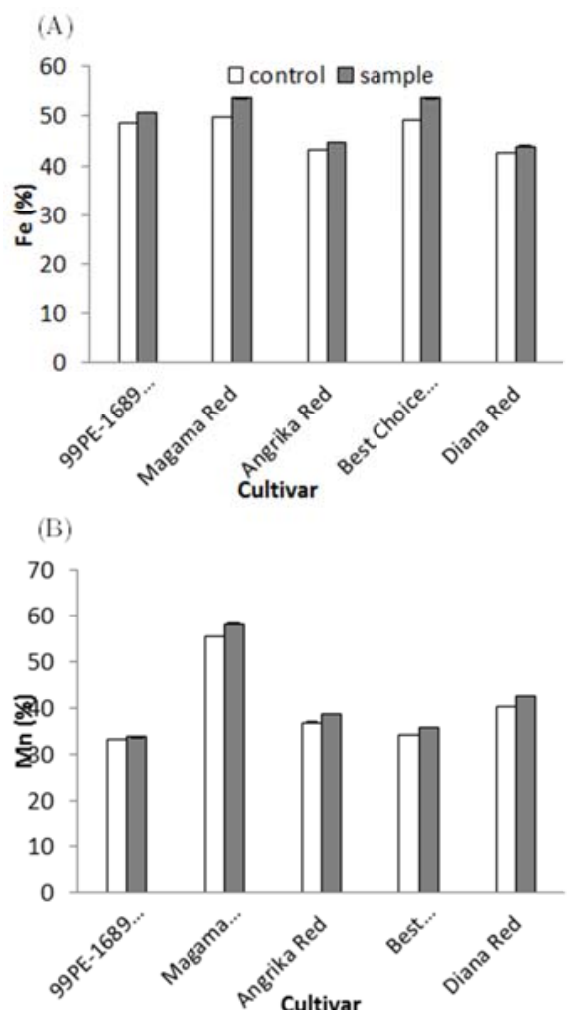

Figure 8. Effect of elevated atmospheric CO2 on micro mineral content of capsicum fruits, (A) Iron (\%) and (B) Manganese (\%). White histograms represent the data for control plants grown at 400 pmol mol-1and black histogram showing result for sample plants grown at $1000 \mu \mathrm{mol}$ mol-1. ns represents non-significant data $(\mathrm{P}>0.1)$ and number in parenthesis indicate trend $(0.05<\mathrm{P} \leqslant 0.1)$.

Table 1. Fatty acids (\%) composition of capsicum varieties grown at two levels of CO2

\begin{tabular}{l|l|l|l|l}
\hline \multirow{2}{*}{ Fatty acids } & \multicolumn{3}{|c|}{$99 \mathrm{PE}-1689$} & \multicolumn{3}{c}{ Best Choice } \\
\cline { 2 - 5 } & \multicolumn{4}{|c}{ concentration $\left(\mathrm{\mu mol} \mathrm{mol}{ }^{1}\right)$} \\
\cline { 2 - 5 } & 400 & 1000 & 400 & 1000 \\
\hline C12:0; Lauric acid & 0.007 & 0.009 & 0.002 & 0.002 \\
\hline C14:0; Myristic acid & 0.036 & 0.045 & 0.020 & 0.038 \\
\hline C15:0; Pentadecanoic acid & 0.002 & 0.002 & 0.002 & 0.003 \\
\hline C16:0; Palmitic acid & 0.231 & 0.197 & 0.391 & 0.345 \\
\hline C16:1c; Palmitoleic acid & 0.007 & 0.006 & 0.006 & 0.005 \\
\hline C17:0; Margaric acid & 0.006 & 0.005 & 0.007 & 0.007 \\
\hline C18:0; Stearic acid & 0.077 & 0.052 & 0.073 & 0.067 \\
\hline C18:1c; Oleic acid & 0.067 & 0.041 & 0.068 & 0.058 \\
\hline C18:1n9t; Elaidic acid & 0.011 & 0.008 & 0.007 & 0.011 \\
\hline C18:2c; Linoleic acid & 0.850 & 0.738 & 1.147 & 0.833 \\
\hline C18:2t; Octadecadienoic acid & 0.012 & 0.009 & 0.023 & 0.011 \\
\hline C18:3n3; Linolenic acid & 0.312 & 0.188 & 0.203 & 0.490 \\
\hline C20:0; Arachidic acid & 0.026 & 0.017 & 0.029 & 0.022 \\
\hline C22:0; Behenic acid & 0.020 & 0.014 & 0.026 & $0.016 i$ \\
\hline C23:0; Tricosanoic acid & 0.004 & 0.002 & 0.004 & 0.003 \\
\hline C24:0; Tetracosanoic acid & 0.019 & 0.014 & 0.019 & 0.012 \\
\hline
\end{tabular}


Table 2. Amino acids (\%) composition of capsicum varieties grown at two levels of CO2

\begin{tabular}{l|l|l|l|l|l|l|l}
\hline \multirow{2}{*}{ Amino acids } & \multicolumn{4}{l|}{ 99PE-1689 } & \multicolumn{2}{l|}{ Magama } & \multicolumn{2}{l}{ Best Choice } \\
\cline { 2 - 7 } & \multicolumn{5}{|c}{$\mathrm{CO}_{2}$ concentration $\left(\mathrm{\mu mol} \mathrm{\textrm {mol } ^ { - 1 }}\right)$} \\
\cline { 2 - 7 } & 400 & 1000 & 400 & 1000 & 400 & 1000 \\
\hline Aspartic acid & 0.085 & 0.079 & 0.227 & 0.202 & 0.237 & 0.140 \\
\hline Threonine & 0.054 & 0.039 & 0.269 & 0.124 & 0.212 & 0.084 \\
\hline Short consensus repeats & 0.051 & 0.050 & 0.149 & 0.147 & 0.212 & 0.147 \\
\hline Glutamic acid & 0.150 & 0.117 & 0.366 & 0.227 & 0.467 & 0.332 \\
\hline Proline & 0.024 & 0.020 & 0.033 & 0.047 & 0.050 & 0.041 \\
\hline Glycine & 0.016 & 0.013 & 0.083 & 0.028 & 0.033 & 0.020 \\
\hline Valine & - & 0.039 & 0.089 & 0.034 & 0.053 & 0.070 \\
\hline Methionine & 0.025 & 0.073 & 0.110 & 0.075 & 0.305 & 0.150 \\
\hline Isoleucine & 0.221 & 0.190 & 0.230 & 0.167 & 0.331 & 0.141 \\
\hline Leucine & 0.209 & 0.178 & 0.389 & 0.259 & 0.127 & 0.107 \\
\hline Tyrosine & 0.093 & 0.078 & 0.157 & 0.120 & 0.046 & 0.075 \\
\hline Phenylalanine & 0.011 & 0.012 & 0.139 & 0.039 & 0.047 & 0.033 \\
\hline Lysine & 0.021 & 0.013 & 0.062 & 0.031 & 0.049 & 0.039 \\
\hline Arginine & 0.016 & 0.023 & 0.079 & 0.081 & 0.077 & 0.043 \\
\hline
\end{tabular}

\section{Discussion}

The purpose of the present study was to evaluate the effect of enhanced atmospheric $\mathrm{CO}_{2}$ on the nutritional composition of different varieties of chili (Capsicum annuum) at two stages of maturity i.e. green and red. It was found that increased atmospheric $\mathrm{CO}_{2}$ caused a nutritional imbalance in all varieties of capsicum at both stages of maturity by increasing sugar content, decreasing protein as well as vitamin $\mathrm{C}$ and disturbing the concentration of many important minerals. Since data on these particular local cultivars is not available, a point to point comparison is not possible, but the trend of change is similar to other plants studied earlier.

Capsicum fruits were picked at maturity. The plants grow and mature faster in elevated $\mathrm{CO}_{2}$ compared to ambient plants. Analyzing fruits of same age for control and sample plants is in fact a comparison between plants of different maturity levels, which surely will be different in their nutritional composition, and will not specifically reflect the effect of elevated $\mathrm{CO}_{2}[17]$. In present experiment, such problems were avoided by comparing fruits harvested at same maturity level and not same age. Fruits were picked at two maturity levels, a fully matured red stage and a premature green stage.

Elevated $\mathrm{CO}_{2}$ increased the number of fruits produced per plant as well as fresh weight of the capsicum fruits, thus increasing the yield substantially. Increase in the number and fresh weight of fruits was different for all the five varieties of capsicum, however, qualitative response of all verities to the elevated $\mathrm{CO}_{2}$ was similar. The results are in agreement with the previous experiments where growth, yield and root/shoot ratio of capsicum plants increased with the enhanced atmospheric $\mathrm{CO}_{2}$ [12, 14]. This is quite expected as any increase in concentration of atmospheric $\mathrm{CO}_{2}$, a raw material for photosynthesis, will increase the rate of photosynthesis, thus increasing the edible biomass, the final product of photosynthesis.

Protein content was different in different varieties of capsicum. Variation in the protein content of different varieties of capsicum was also noted by[18]. Nutritional quality of capsicum was negatively affected by enhanced $\mathrm{CO}_{2}$, in terms of protein content. No such reduction in protein has been previously reported for capsicum, however it was observed for a number of other food plants like potato, rice and soybean[19, 20]. This reduction could be a result of increased amount of nonstructural carbohydrates due to increased photosynthesis leading to dilution as well as increased water use efficiency. This could be coupled with decreased rate of transpiration leading to a reduction in nitrogen uptake by leaves, as a result decreasing protein content of crops and vegetables. 
Carbohydrates are major components of the capsicum. Reducing sugars (glucose and fructose) are the main sugars in capsicum as compared to non-reducing sugars (sucrose). The green stage sugar content was determined only for 99PE-1689. It was observed that red stage has higher amount of sugar content as compared to green stage. The result is in agreement with the previous studies by Martinez et al.[21] who proposed that with fruit maturity, changes in action of cell wall degrading enzymes result in accumulation of sugars and carbohydrates in the cell walls. Sugar content of the capsicum was significantly increased by elevated $\mathrm{CO}_{2}$, however the increase was non-significant for non-reducing sugars. Increase in sugars is higher for red stage of 99PE-1689 as compared to its green stage.

Effect of enhanced $\mathrm{CO}_{2}$ on sugar and carbohydrate content of capsicum is not reported, however increase is observed for other crops and vegetables[20, 22]. Increase in carbohydrate concentration is not unexpected as enhanced atmospheric $\mathrm{CO}_{2}$ leads to increase in photosynthesis, resulting in greater amount of plant non-structural carbohydrates leading to relatively more carbon based secondary compounds.

Fiber content of capsicum was higher and was almost similar for green and red stages of all varieties, results being in agreement with the previous work by Martinez et al. [21] Increase in the fiber content followed a trend for green stages and was significant for red stages. Although the fiber contents of red and green stages were not much different, the effect of elevated $\mathrm{CO}_{2}$ on fiber content was much pronounced for red stage as compared to the green stage.

Vitamin $\mathrm{C}$ is a very important constituent of capsicum, found in more quantity in red stage as compared to the green stage. Vitamin $\mathrm{C}$ contents of two varieties, among a total of five, fall within the range of Recommended Dietary Allowance (RDA) (60-90 mg/day). Vitamin C contents of the rest of the three varieties were slightly below the required amount. Enhanced atmospheric $\mathrm{CO}_{2}$ decreased vitamin $\mathrm{C}$ contents of all varieties significantly. The reduction for red stage was slightly more than the green stage of the corresponding variety. Capsicum is a very important source of vitamin $\mathrm{C}$ and its vitamin contents are comparable to the other recognized good sources this vitamin[23]. In our experiments, elevated $\mathrm{CO}_{2}$ adversely affected nutritional quality by decreasing Vitamin $\mathrm{C}$ content of capsicum fruit.

Total titratable acidity, which represents organic acid content in the fruit, was higher at the red stage as compared to green stage, results similar to previous findings [21]. Acidity of capsicum was not affected by atmospheric $\mathrm{CO}_{2}$, although a small decrease in acidity of both red and green stages was observed but the decrease was statistically non-significant.

Mineral composition of capsicum varieties was altered by elevated $\mathrm{CO}_{2}$. Hydrogen was increased, while $\mathrm{Ca}$ and $\mathrm{Mg}$ decreased, while no effect was observed on $\mathrm{S}$ and $\mathrm{K}$ concentration. Amongst the micro minerals, $\mathrm{Zn}$ decreased, Fe and $\mathrm{Mn}$ increased while no significant effect was observed on $\mathrm{Cu}$ content. $\mathrm{Cu}$ followed a trend $(0.05<P \leqslant 0.1)$ in 99PE-1689. Hydrogen along with $\mathrm{C}$ is the main constituents of carbohydrates and increase in $\mathrm{H}$ may be due to increase in carbohydrates concentration with enhanced atmospheric $\mathrm{CO}_{2}$. Reduction in Nitrogen and other minerals could be a result of dilution caused by increase in non- structural carbohydrates, or a decrease in the uptake of minerals due to reduced transpiration from leaves with elevated $\mathrm{CO}_{2}[24]$. Increase in important nutrients like Fe and $\mathrm{Mn}$ with elevated $\mathrm{CO}_{2}$ is favorable, but at the same time reduction in $\mathrm{Ca}, \mathrm{Mg}$ and $\mathrm{Zn}$ could adversely affect the nutritional quality of capsicum fruit.

In our experiment, the major fatty acids found in capsicum were Palmitic, linoleic and linolenic acid. These results are in agreement with previous work of Cook et al.[18]. He determined chemical composition of 13 varieties of capsicum and found that linoleic and linolenic acid were major fatty acids. Enhanced atmospheric $\mathrm{CO}_{2}$ affected all the three major fatty acids of capsicum. Palmitic and linoleic acids decreased for both varieties while linolenic acid decreased for one variety only. Linoleic and linolenic acids are essential fatty acids, as they are not only used as fuel but also play important role in biological processes in human body. Human body is unable to synthesize these acids and they must be taken in the diet. Decrease in concentration of fatty acids by elevated $\mathrm{CO}_{2}$ is also in agreement with the reduction in crude fat content of capsicum varieties. Decrease in concentration of essential fatty acids will lower the nutritional quality of capsicum fruits in future $\mathrm{CO}_{2}$ enriched atmosphere.

The decrease in amino acid concentration with elevated $\mathrm{CO}_{2}$ observed in this work has not been reported for Capsicum. The reduction in present experiment is in accordance with the earlier reported decrease in amino acid contents of potato tuber [20] and wheat grains [25]. Reduction in amino acid 
contents, especially the essential amino acids like isoleucine, leucine, phenylalanine, lysine, threonine and tyrosine under elevated $\mathrm{CO}_{2}$ conditions will lower the nutritional quality of capsicum.

\section{Conclusions}

The nutritional quality of the capsicum was affected by elevated $\mathrm{CO}_{2}$ in the present experiment. The general trend is that important nutritional parameters including protein and vitamin $\mathrm{C}$ were negatively affected by enhanced atmospheric carbon dioxide, while sugars and fibers were increased. This is an alarming factor for the modern world where most of the people search for protein rich diet and want to avoid sugars and carbohydrates especially in case of diabetic patients. Mineral and essential fatty acid content of capsicum varieties was also altered with enhanced atmospheric $\mathrm{CO}_{2}$ with a general reducing trend. Among minerals, $\mathrm{Ca}, \mathrm{Mg}$ and $\mathrm{Zn}$ contents of all five capsicum varieties are reduced which may increase the chances of hidden hunger. Reduction in important minerals is usually thought to be a result of nutritional dilution which is caused by increase in non-structural carbohydrates in $\mathrm{CO}_{2}$ enriched air. Another reason might be reduced transpiration which in turn decreased the rate of uptake of important minerals from soil. Important essential oils like Palmitic, linoleic and linolenic acid were also negatively affected in $\mathrm{CO}_{2}$ enriched atmosphere. Essential fatty acids must be taken through diet as human body is unable to synthesis them. Decrease in concentration of essential fatty acids will lower the nutritional quality of capsicum fruits in future $\mathrm{CO}_{2}$ enriched atmosphere. The biochemical response of different varieties of capsicum to $\mathrm{CO}_{2}$ enrichment is the same qualitatively; however its quantitative response is not exactly the same. Although our data is on a limited scale, the message is loud and clear that food quality will be negatively affected by the $\mathrm{CO}_{2}$ build up in the atmosphere. The data on $\mathrm{CO}_{2}$ enriched air obtained so far support the hypothesis that breeding new crop varieties along with better crop management are possible measures to combat the eminent food security threat with the climate change.

Acknowledgment. The authors gratefully acknowledge research facilities provided by Barani Agriculture Research Institution (BARI), Chakwal, Pakistan and financial support by the Higher Education Commission (HEC), Islamabad.

\section{References}

1. Keeling, R.F., et al., Carbon Dioxide Research Group,, 2008, Scripps Institution of Oceanography, University of California: California.

2. IPCC, IPCC(2007), in Climate Change. The Physical Science Basis. Contribution of Working Group I to the Fourth Assessment Report of the Intergovernmental Panel on Climate Change. Intergovernmental Panel on Climate Change, Cambridge Univ. Press2007.

3. Allen Jr., L.H., et al., Advances in Carbon Dioxide Research. ASA Special Publication 611997. 179-228.

4. DaMatta, F.M., et al., Impacts of climate changes on crop physiology and food quality. Food Res. Int., 2010. 43(7): p. $1814-1823$.

5. Kimball, B.A., K. Kobayashi, and M. Bindi, Responses of agricultural crops to free-air CO2 enrichment. Adv. Agron., 2002. 77: p. 293-368.

6. Leakey, A.D.B., et al., Elevated CO2 effects on plant carbon, nitrogen, and water relations: Six important lessons from FACE. J. Exp. Bot., 2009. 60(10): p. 2859-2876.

7. Bosland, P.W., Capsicums: Innovative uses of an ancient crop. Progress in new crops. ASHS Press, Arlington, VA, 1996: p. 479-487.

8. Hägg, M., S. Ylikoski, and J. Kumpulainen, Vitamin C and alfa- and beta-carotene contents in vegetables consumed in Finland during 1988-1989 and 1992-1993. J. Food Comp. Anal, 1994. 7: p. 252-259.

9. Howard, L.R., et al., Changes in phytochemical and antioxidant activity of selected pepper cultivars (Capsicum species) as influenced by maturity. J. Agric. Food. Chem., 2000. 48: p. 1713-1720.

10.Mulchi, C.L., et al., Growth and physiological characteristics of soybean in open-top chambers in response to ozone and increased atmospheric CO2. Agr. Ecosyst. Environ., 1992. 38(1-2): p. 107-118.

11.Rajput, J.C. and Y.R. Parulekar, El pimiento, in Tratado de Ciencia y Tecnologia de lashortalizas, D.K. Salunkhe, Editor 2004, Zaragoza, Spain: Acriba. p. 203-225. 
12.Penuelas, J., et al., Detrimental effects of fluctuating high CO2 concentrations on peppers. Photosynthetica, 1995. 31: p. 361-370.

13.Janes, B.E., Effect of carbon dioxide, osmotic potential of nutrient solution, and light intensity on transpiration and resistance to flow of water in pepper plants. Plant Physiol., 1970. 45: p. 95-103.

14.Furlan, R.A., et al., Effect of irrigation water depth and CO2 application on sweet pepper yield cv. Mayata in plastic greenhouse. Horticultura Brasileira, 2002. 20(4): p. 547-550.

15.Aloni, B., et al., The effect of high temperature and high atmospheric CO2 on carbohydrate changes in bell pepper (Capsicum annuum) pollen in relation to its germination. Physiol. Plantarum 2001. 112: p. 505-512.

16.Grodzinski, B., et al., Regulating plant/insect interactions using CO2 enrichment in model ecosystems. Adv. Space Res., 1999. 24: p. 281-291.

17.Taub, D.R. and X. Wang, Why are Nitrogen Concentrations in Plant Tissues Lower under Elevated CO2? A Critical Examination of the Hypotheses. J. Integr. Plant Biol., 2008. 50(11): p. 1365-1374.

18.Cook, J.A., et al., Nutrient and chemical composition of 13 wild plant foods of Niger. J. Food Comp. Anal., 2000(13): p. 83-92.

19.Taub, D.R., B. Miller, and H. Allen, Effects of elevated CO2 on the protein concentration of food crops: a metaanalysis. Global Change Biol., 2008. 14(3): p. 565-575.

20.Högy, P. and A. Fangmeier, Atmospheric CO2 enrichment affects potatoes: 2. Tuber quality traits. Eur. J. Agron., 2009. 30(2): p. 85-94.

21.Martinez, S., et al., The composition of Aronia peppers (Capsicum anuum L.) at different stages of maturity. Int. J. Food Sci. Nutr., 2007. 58(2): p. 150-161.

22.Islam, M.S., T. Matsui, and Y. Yoshida, Effect of carbon dioxide enrichment on physico-chemical and enzymatic changes in tomato fruits at various stages of maturity. Sci. Hort., 1996. 65(2-3): p. 137-149.

23.Hägg, M., S. Ylikoski, and J. Kumpulainen, Vitamin C and alfa- and beta-carotene contents in vegetables consumed in Finland during 1988-1989 and 1992-1993. J. Food Comp. Anal., 1994. 7(252-259).

24.Gifford, R.M., D.J. Barrett, and J.L. Lutze, The effects of elevated [CO2] on the C:N and C:P mass ratios of plant tissues. Plant. Soil, 2000. 224(1-14).

25.Högy, P., et al., Grain quality characteristics of spring wheat (Triticum aestivum) as affected by free-air CO2 enrichment. Environ. Exp. Bot. DOI: 10.1016/j.envexpbot.2011.12.007, 2011. 